\title{
Media Discourses and Communal Stances on Climate Change in Cameroon
}

\author{
Julius M. Angwah \\ University of Yaounde I, Cameroon
}

\begin{abstract}
Climate change is arguably one of the most unforeseen threats of the $21^{\text {st }}$ century. More than ever before, national and international conferences are organised regularly with heated political debates on why, who, how and when to frame polices with eco-protective strategies. In the face of these heated political debates, the role of the media in informing public opinion on the stakes of the crisis is indispensable. While the media mitigate and communicate climate change stories, there are observable discrepancies and diverse communal stances on the issue. The present study investigates the frequency and mitigation of media transmission of climate change realities in four leading Cameroonian newspapers and the stances of vulnerable locals towards the issue. From a corpus-based perspective, 30 editions of three Cameroonian leading newspapers published between the months of April and June 2018 were closely analysed to find out the frequency of publication and the degree of mitigation of climate change stories. Three publishers and 200 farmers were interviewed to ascertain their stances on the issue. The results revealed a relatively insignificant recurrence of climate change stories which stems from publishers' subjective categorisation of "current" news in the country. Informed farmers perceived the issue as a distinct domestic phenomenon with a possible national effect, while their uninformed counterparts attributed the crisis to the natural order of climatic variation on planet earth. Such perceptions certainly inhibit against effective agencies to climate change solutions.
\end{abstract}

Keywords: Media Discourses, Communal Stances, Climate Change, Cameroon

DOI: $10.7176 / \mathrm{RHSS} / 9-11-06$

Publication date:June $30^{\text {th }} 2019$

\section{Introduction}

Climate change is perhaps the most unanticipated threat of the $21^{\text {st }}$ century, with well-known ramifications for earth's ecosystems at different levels. More than ever before, mankind is confounded in the face of the increasing and devastating consequences of the crisis and, indeed, almost helpless in effectively managing it. Barack Obama, in 2006, remarked that, "the issue of climate change is one that we ignore at our own peril." Obama's fears, and indeed those of so many others, are, perhaps, in response to the $4^{\text {th }}$ assessment report of the intergovernmental panel on climate change which, relative to previous reports, "warn[s] the international community that the increase in anthropogenic greenhouse gases emissions will result in global climate change" (Roudier et. al. 2011:1073). Barely few years later, the world came face-to-face with the stark realities of climate change and, today, it is a current and a major concern in the seven continents that make up the world.

The gravity of the crisis has increasingly informed many international and national policies (Mburia, 2015) that seek to guide the preservation and protection of the ecosystem. Observably, administrative authorities are mostly at the helm in the framing and implementation of such policies, which are often transmitted to local and vulnerable population through the media. Even at that, it is not quite clear how often the media, especially Cameroonian leading newspapers, educate locals on climate change realities, agencies and solutions.

Consequently, there are observably varied discrepancies in the frequency and mitigation of news stories on climate change, as well as diverse stances among vulnerable persons in Cameroon who, besides the agricultural difficulties they experience as a result of the crisis (UNDP Human Development Report, 2007/2008), are also victims of the extremely scorching dry-seasons and the torrentially blustery rainy-seasons, a relatively eccentric phenomenon which inhibit against their socio-economic activities. A senior journalist of the Network of Climate Journalists of the Greater Horn of Africa (NECJOGHA), once remarked in a report on "Communicating Climate Information" that "millions of farmers are grappling with the changing climate around them but are starved of real, timely information on what their options are" (Tagbo 2010:6). In Cameroon, for example, it can be observed that farmers have limited access to information on climate change. The concern then is how often Cameroonian leading newspapers present climate change stories. We are equally unsure of the stances of newspaper publishers and those of vulnerable persons towards the issue, and whether media mitigations of the discourse have an effect on vulnerable stakeholders' stances on the crisis.

\section{Trends in climate change discourse}

Discourses on climate change cannot be fairly traced to a particular historical time. This is so because mankind, from time immemorial, has always been concerned about the weather and climatic conditions. Climate change discourses, however, began gaining a well-coordinated and focused attention from the late $18^{\text {th }}$ century when 
geologists found evidence of a succession of geological ages with changing climate (Ripple et al., 2017). Scientific conclusions, at the time, undermined the role of humans in climatic alterations (Spencer, 2011), a view which is observably still shared by many today. Increasingly, however, mankind has come to realise that climate change is real and man, who is at the centre of the crisis, can manage it (Roudier et. al., 2011:1073). Even at that, there are too many controversies that characterise the debate on whether the crisis is real or not; and if it is, who should address it? And how should it be addressed? Current linguistic debates on the issue have projected various concerns, from attitudinal, through the testing of Down's model of Issue Attention Cycle, to the role of the media and the stances of major stakeholders.

Attitudinally, there are believers and non-believers of climate change as a problem. Swaffield (2012:61) remarks that the "frequent response to the problem of climate change is that there is no problem at all." Essentially, there are two categories of ideas in this domain - a complete rejection of the realities of climate change and the claim that climate change is a good thing. Doulton and Brown (2009:194), for example, focus on "broadsheet" newspapers and optimism discourses and argue that climate change is beneficial for development. Swaffield (2012:61) further observes that "among the most prominent cases of climate change denial have been those associated with industry and "big business". It is not surprising since such "big businesses" emit the most quantity of fossil gasses into the atmosphere. Such "big businesses" have often used the media to reject the realities of climate change (Antilla 2005; Gavin \& Marshall, 2011) since discourses against climate change do not pledge any success in their businesses.

While such pessimist stance may discourage efforts to combat the crisis, there are even more convincing arguments that climate change is a reality and should be addressed. Climate change has continuously been perceived as a serious problem mankind is obliged to grapple with (IPCC, 2007). Swaffield (2012:63) argues that climate change is "too big a problem for us to handle". In an effort to project the realities and likely consequences of the crisis, sub-discourses, including "alarmism" (Erenaut \& Signit, 2006), "alarmist defeatism" (Hobson \& Niemeyer, 2011), "disaster strikes" (Doulton \& Brown, 2009), "catastrophe" (Lovelock, 2006) and "Looming tragedy" (Dryzek, 1997), have emerged within the domain of climate change discourse. While these terminologies suggest fear, Signit (2006:13) has further reported that religious registers, including "doom, death and judgement" are also used to describe the likely outcome of the crisis. Such discourses of fear, which is expressed through the "increasingly dominant portrayal of anthropogenic global climate change" (Hulme, 2008:10), undoubtedly emphasise the dire need for the crisis to be taken even more seriously.

Other linguistic approaches to climate change have so far tested Down's model of Issue Attention Cycle (Trumbo, 1996). Down's model is built on three major ideas. First, there is a pre-problem stage in which experts recognise that a problem exists, but the public is not yet aware of it. Second, there is an alarmed discovery and euphoric enthusiasm, during which the public becomes aware and alarmed about the problem, but confident of society's ability to resolve it, an optimism which according to Down, is driven by an American tradition of viewing most obstacles as external rather than intrinsic to societal structure. Third, while the public soon realizes the cost effects and how difficult it could be to solve it, politicians realize that the problem may even be caused by a condition that benefits society.

Media mitigation of climate change discourses has been another interesting linguistic perspective to the issue. In fact, most linguistic studies on climate change have been media-oriented. Boykoff \& Boykoff (2004), for instance, assessed media biases on climate change, Brossard et al. (2004) compared variations of media coverage among nations, Mundo (2012) investigated thematic constructions and lexical preferences in Cameroon Tribune and The Post newspapers, and argued that transitivity is given more prominence to modality. Angwah (2018) analysed media reports, besides other data, and argued that climate change discourse is more of a regional than a national phenomenon.

Even with the seemingly elaborate research energy in climate change discourse, the frequency of media publication and degree of mitigation of climate change stories, as well as vulnerable communal stances on the issue are yet to enjoy adequate scholarly attention in Cameroon. As at the time when the present study was conducted, there seemed to be no conscious effort in Cameroon to elaborately explore the recurrence and mitigation of climate change stories in Cameroonian leading newspapers, and to assess rural and urban responses to the issue at stake. These, in a nutshell, are the major preoccupations of the present study.

\section{Material and Method}

10 editions of three Cameroonian leading newspapers of English expression (The Post, The Guardian Post and The Horizon), published between the months of April and June 2018 were randomly selected for analyses. In all, there were a total of 30 newspaper issues. Each of the editions was closely studied to find out if they had at least an article on climate change. After the identification and tabulation of the relative frequencies, the identified climate change stories were read, typed and converted to plain text format for further analyses with AntConc. In all, the entire corpus was made up of 3215 words. In the course of reading selected news stories on climate change, sample mitigating devices were noted and later tested for frequency and concordances. Results from the 
three sets of newspapers were compared and tabulated.

The publishers of the three newspapers and 200 randomly selected farmers were interviewed. 100 informants were based in Bamenda and 100 others in Mankon, Mbengwi, Bali and Bafut, which are all rural communities in the North West Region of Cameroon. The qualification and categorisation of informants were strictly based on their areas of dwelling. All the informants had spent at least 15 years in their respective dwellings and while the rural inhabitants were mostly subsistent farmers, urban informants were drawn from different social strata. While the three publishers were asked questions on their stances, the frequencies and motives of publishing climate change stories, the 200 randomly selected informants were asked questions on their awareness of the effects of climate change on them as well as their perspectives to climate change solutions.

\section{Results}

A close study of the 30 randomly selected newspapers revealed a paucity of climate change stories. In fact, only five of the 30 newspaper issues carried news stories on climate change. A large chunk of the newspapers' contents was politically-oriented. The following table presents the distribution of climate change stories on the 30 newspapers we considered for analyses.

Table 1: Distribution of climate change news stories on newspapers

\begin{tabular}{lllll}
\hline Newspapers & $\mathbf{N}^{\mathbf{0}}$ of NPs & Freq. of $\mathbf{C C}^{\mathbf{2}}$ stories & Rel. $\%$ & No. Words \\
\hline The Post & 10 & 2 & $40 \%$ & 1438 \\
The Guardian Post & 10 & 3 & $60 \%$ & 1777 \\
The Horizon & 10 & 0 & $00 \%$ & 00 \\
Total & $\mathbf{3 0}$ & $\mathbf{5}$ & $\mathbf{1 0 0} \%$ & $\mathbf{3 2 1 5}$ \\
\hline
\end{tabular}

Even in editions where news stories on climate change were found, such stories did not feature on the frontline pages. In all the 30 newspaper issues studied, the front pages carried headlines that were mostly politically-oriented with asymmetrical social and administrative issues. While this could be based on the current socio-political crisis wrecking Anglophone Cameroon, climate change is also quite important to be ignored even under the category of what is often considered in journalistic language as "minor" news. This suggests two things - either the publishers do not see the need for regular publication of news stories on climate change or they just do not have access to current information on the issue which they can disseminate.

The 5 climate change stories were closely read and various stance devices (hedges and boosters) were identified. In table 2 below, we present some of the hedging epistemic usages in news stories that were analysed.

Table 2: Hedges in Newspaper Climate Change Reports

\begin{tabular}{lll}
\hline Hedges & Freq. & \% \\
\hline Assume & 5 & $5.37 \%$ \\
Believe & 3 & $3.22 \%$ \\
Should & 7 & $7.52 \%$ \\
Would & 10 & $10.75 \%$ \\
Could & 5 & $5.37 \%$ \\
Possible & 2 & $2.15 \%$ \\
It is not quite clear whether... & 3 & $3.22 \%$ \\
$\ldots$..could be based on the fact that... & 3 & $3.22 \%$ \\
We & 15 & $16.12 \%$ \\
Agentless passives & 17 & $18.27 \%$ \\
References & 23 & 24.73 \\
Total & 93 & $100 \%$ \\
\hline
\end{tabular}

As indicated on the table above, 93 of the total 3215 words in the corpus were hedges used to mitigate various propositions, and this was either due to the author's limited knowledge on the subject matter, the desire to effectively attribute authorial responsibility or merely as a strategy for decreasing fuzziness. Consider, for instance, the following textual examples that clearly demonstrate these three mitigating functions of hedges in the corpus.

1. These reveal that net revenues could rise by up to $\$ 2.9$ billion if future climates are mild and wet but could fall by up to $\$ 12.6$ billion if they are hot and dry. (TPNP $1^{3}$ )

2. President Paul Biya invited the international community to go beyond the debate on responsibility between the industrialised and developing countries, adding that the reduction of greenhouse gas emissions remains conditional on the support of the international community. (TGPNP1 ${ }^{4}$ )

\footnotetext{
NPs: Newspapers

${ }^{2} \mathrm{CC}$ : Climate change

${ }^{3}$ TPNP1: The Post Newspaper, number one.

${ }^{4}$ TGPNP1: The Guardian Post Newspaper, number one
} 
3. Even though the forest is under threat, Green Peace Africa believes working with educational institutions in creating urban green spaces is a foundation for future leaders to stem deforestation... (TGPNP1)

The use of the epistemic modal verb, "could," in example 1 above, suggests the author's uncertainty of the possible turn out of events. By making reference to President Paul Biya as seen in example 2 above, the author of the report attributes the responsibility of the claim to an agent other than himself. The last example projects the relativity of the claim to a particular subject and insists that the belief is shared by members of the Green Peace Africa and not necessarily by everyone. Even with the use of such hedging devices, all five stories merely reported administrative claims on climate change; neither of them was an exhaustive story on climate change realities in various parts of the country, nor an assessment of the practical efforts to national climate change solutions.

Besides hedges, boosters were also used in the various reports as presented on the following table.

Table 3: Boosters in newspaper climate change reports

\begin{tabular}{lll}
\hline Boosters & Freq. & $\mathbf{\%}$ \\
\hline Will & 8 & $16.66 \%$ \\
Must & 3 & $6.25 \%$ \\
Need to & 2 & $4.16 \%$ \\
Establish & 5 & $10.41 \%$ \\
Clear & 9 & $18.75 \%$ \\
Proper & 4 & $8.33 \%$ \\
There are indicators that... & 4 & $8.33 \%$ \\
$\ldots$ is determined to... & 8 & $16.66 \%$ \\
It is quite evident that... & 3 & $6.25 \%$ \\
We cannot doubt the fact that... & 2 & $4.16 \%$ \\
\hline Total & 48 & $100 \%$ \\
\hline
\end{tabular}

Boosters were used as mitigating devices to show authors' confidence in their propositions. The following example shows the author's conviction in the truth value of their proposition:

4. Climate change in Cameroon has had, and will continue to have, adverse effects on agro-ecosystems and communities in multiple ways; with negative consequences dominating. (TGPNP1)

All the booster devices identified suggest the authors' convictions as exemplified in (4) above. Angwah (2018:205) contends that, "such predictions are often the effects of convincing evidence" which could be justified to some extent. Consequently, the epistemic modal auxiliary, "will" "boosts the confidence, inherent in the claim and thus assures the listener or reader to identify with the truth value or degree of truthfulness in the proposition" (opcit). The other boosters we tested were all used for the same purpose.

From the statistics presented above, we notice that Cameroonian leading newspapers are more likely to hedge climate change claims than boost them, as could be seen on the following figure that clearly shows the quantitative differences of hedges and boosters in the corpus.

Figure 1: Quantitative differences between hedges and boosters

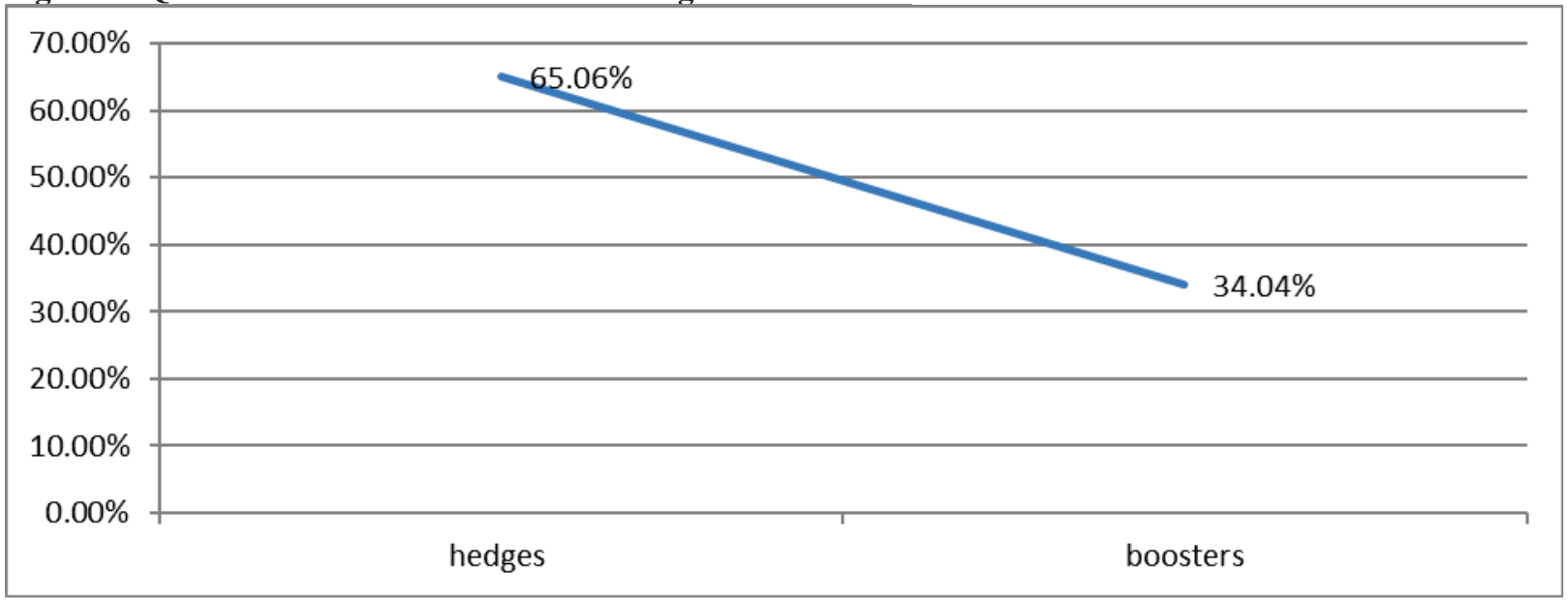

\section{Publishers' stances on climate change: urban and rural responses}

Micro perspectives to global climate change solutions are effervescent. Consequently, for there to be a genuine global participation in eco-preservation, there must be a certain degree of micro awareness. The two sets of informants, publishers and rural/urban inhabitants, who were interviewed on various fundamental basics of 
climate change realities and effects, had interesting views on the issue.

First, the three publishers agreed on a number of issues. They do not publish climate change stories regularly because of more current and pressing socio-political issues in the country. They argued that as a result of the crisis, there are even less talks on climate change which also leads to a paucity of stories on the issue. This could explain why even when climate change news is published, it is either a report on a meeting or tree-planting exercise, and hardly ever an in-depth story on the climate change crisis. From such weak backgrounds, there could hardly be any thorough appraisal of the crisis, and this could justify why the reports are most likely to be hedged than boosted. This also suggests that in Cameroon, socio-political news is given more prominence than environmental issues, especially at a time like this when the country is faced with the Anglophone Crisis and mounting pressures from both Cameroonian opposition political parties and the international community. The situation was, however, different with regard to the 200 other informants. $5(2.5 \%)$ of the 200 rural informants, for instance, said they were hearing of the phrase "climate change" for the first time. With regard to whether climate change is real or not, they all agreed that it is real, but did not see it in exactly the same way. 54 (54\%) of the 100 Urban informants (UI) and 35 (35\%) of the rural informants (RI) considered the crisis as a domestic issue with possible national and even international ramifications. The other informants (46 (46\%) urban informants and $75(75 \%)$ rural informants) considered it as the natural alternation of climatic order. On whether it should be taken seriously or not, all the informants think it should. With regard to what could be done; while some (54 (54\%) urban informants and $35(35 \%)$ rural informants) felt that more trees could be planted and the cutting of trees minimized, the others (46 (46\%) UI and $75(75 \%) \mathrm{RI})$ were not quite sure of what needs to be done. In short, they suggested that there is almost nothing to be done about it because it is the natural climatic order of which man has no influence over it. This view was popular in the $18^{\text {th }}$ century western society (Spencer, 2011), and that it is still held today suggests that many Cameroonians are yet to come to terms with the stark realities of climate change. Even at that, over the years, mankind has come to realise that its activities, through the emission of fossil gasses, are affecting the planet and, therefore, sees the dire need for more integrated and micro approaches to climate change solutions.

\section{Discussions and Conclusion}

The paucity of newspaper publications on climate change stories somewhat correlates with the degree of awareness of climate change in rural and urban settings in Cameroon. Consequently, the diverse beliefs about the issue are partly informed by the epileptic publication or discussion of climate change stories. Even where climate change news is published, it is hardly an exhaustive account of the stark realities in the country or elsewhere, but rather slender information which hardly passes for an exhaustive and realistic story on the issue. The discourse is generally mitigated to mark uncertainty or confidence, to adequately attribute authorial responsibility to claims and generally to decrease fuzziness. There is, however, the dire need for more recurrent publication of contextual realities of climate change that could inform and inspire Cameroonians to effectively contribute to climate change solutions. The urgency of climate change requires a prominent voice even amidst crisis situations. Consequently, media organs should necessarily designed policies that stimulate individual and collective agencies towards climate change solutions.

\section{References}

Angwah, J. (2018). Stance in West African and Asian Climate Change Discourses: A Corpus-Based Appraisal. Unpublished PhD Thesis, University of Yaounde I.

Boykoff M.T and Boykoff J.M (2004). "Bias as balance: global warming and the US prestige press." Global Environmental Change. 14: 125-36.

Brossard, D., Shanahan, J., and McComas, K. (2004). "Are issue-cycles culturally constructed? A comparison of French and American coverage of global climate change." Mass Communication and Society. 7 (3): 359 377.

Fairclough, N. (1992). Discourse and Social Change, Cambridge: Polity Press.

Grundmann, R. and KRISHNAMURTHY, R. (2010). "The Discourse of Climate Change: A Corpus-based Approach." Critical Approaches to Discourse Analysis across Disciplines. 4 (2): 125 - 146

Jorgensen, M. and Louise, J. P. (2002). Discourse Analysis as Theory and Method. SAGE Publications Ltd 6 Bonhill Street London EC2A 4PU

Mundo, L. (2012). “Media Biases of Climate Change in Cameroon Radio and Television Station”. Unpublished MA Dissertation, University of Yaounde 1.

Ripple WJ, Wolf C, Newsome TM, Galetti M, Alamgir M, Crist E, Mahmoud MI, Laurance WF (13 November 2017). “World Scientists' Warning to Humanity: A Second Notice.” BioScience.

Spencer Weart (2011). "The Public and Climate Change.”. The Discovery of Global Warming.

Trumbo, C. (1996). "Constructing climate change: Claims and frames in US news coverage of an environment issue." Public Understanding of Science. 5: 269-283 